Real Options Analysis and Strategic Decision Making

Author(s): Edward H. Bowman and Gary T. Moskowitz

Source: Organization Science, Vol. 12, No. 6 (Nov. - Dec., 2001), pp. 772-777

Published by: INFORMS

Stable URL: http://www.jstor.org/stable/3086047

Accessed: 06/07/2009 03:58

Your use of the JSTOR archive indicates your acceptance of JSTOR's Terms and Conditions of Use, available at http://www.jstor.org/page/info/about/policies/terms.jsp. JSTOR's Terms and Conditions of Use provides, in part, that unless you have obtained prior permission, you may not download an entire issue of a journal or multiple copies of articles, and you may use content in the JSTOR archive only for your personal, non-commercial use.

Please contact the publisher regarding any further use of this work. Publisher contact information may be obtained at http://www.jstor.org/action/showPublisher?publisherCode=informs.

Each copy of any part of a JSTOR transmission must contain the same copyright notice that appears on the screen or printed page of such transmission.

JSTOR is a not-for-profit organization founded in 1995 to build trusted digital archives for scholarship. We work with the scholarly community to preserve their work and the materials they rely upon, and to build a common research platform that promotes the discovery and use of these resources. For more information about JSTOR, please contact support@jstor.org. 


\title{
Real Options Analysis and Strategic Decision Making
}

\author{
Edward H. Bowman \\ (deceased) \\ formerly at The Wharton School, University of Pennsylvania \\ Gary T. Moskowitz \\ Edwin L. Cox School of Business, Southern Methodist University, P.O. Box 750333, Dallas, Texas 75275-0333 \\ gmoskowi@mail.cox.smu.edu
}

\begin{abstract}
The real options approach is frequently advocated as an approach that offers a positive and radical reassessment of the value of risk and exploration. We examine a recent case where Merck used the real options approach to justify an investment in an $\mathrm{R} \& \mathrm{D}$ project. This case is used to highlight some of the problems associated with using real options. We note that the assumptions incorporated in most standard option valuation models can conflict with the conclusions reached by strategic analysis. As a result, users of real options models should understand the quantitative aspects of these models, and may often need to create a customized model for each situation. The difficulty of developing customized models may explain, in part, the limited use of the real options approach in strategic analysis. (Real Options; Decision Making; Research and Development; Strategic Analysis)
\end{abstract}

The investment decision represents a stylized description of the critical process by which organizations commit resources to future growth. Though such decisions are subject to a variety of internal pressures (see Cohen et al. 1972), companies nevertheless portray the investment decision as the outcome of a formalized process that employs explicit rules of valuation. It is unlikely that these rules are language games without real consequences (Astley 1985). Indeed, the teaching of financial methods is a pivotal component in the education of a MBA student.

Organizational theories and financial theories of investment valuation are rarely considered in tandem. Yet, they both have shared common treatments of risk as undesirable. Traditional corporate finance theory suggests that firms should use a discounted cash flow model (DCF) to analyze capital allocation proposals. Under this approach, the estimated cash flows from an investment project are discounted to their present value at a discount rate that reflects the market price of the project's risk. Higher systematic risk reduces the attractiveness of a project. If a proposal has a positive present value, then the project should be funded. Unfortunately, this approach does not properly account for the flexibility that may be present in a project. For example, managers can increase the size of a production operation in response to higher-thanexpected levels of demand, or cut funding for a research project that is not inventing marketable products. This flexibility has value-a value that is not captured by the traditional DCF methodology.

The real options approach has been suggested as a capital budgeting and strategic decision-making tool because it explicitly accounts for the value of future flexibility (Trigeorgis 1996, Amram and Kulatilaka 1999). Real options models are based on the assumption that there is an underlying source of uncertainty, such as the price of a commodity or the outcome of a research project. Over time, the outcome of the underlying uncertainty is revealed, and managers can adjust their strategy accordingly.

Despite the theoretical attractiveness of the real options approach, its use by managers appears to be limited. In some commodity-based operations, such as oil and mining, the real options approach appears to have gained some use by sophisticated companies (Coy 1999). In more strategic contexts, however, options' analytic techniques are less frequently used (Copeland and Keenan 1998, Lander and Pinches 1998). In fact, when Merck \& Co., Inc. recently used the Black-Scholes option valuation model to assess a proposed investment, its use of this analytic technique received attention in business publications, which 
found this to be newsworthy (e.g., Nichols 1994, Sender 1994, Thackray 1995).

This article examines some of the practical organizational issues associated with the use of real options analysis. We note many of the practical difficulties managers face in using real options techniques in strategic decision making. We illustrate some of these problems using Merck's recent real options calculation as an example. This example shows how the results of strategic analysis can differ from the assumptions of a typical options model. As a result, the use of a standard options model in a strategic analysis could lead to poor strategic decisions. We conclude with a discussion of the role of options analysis in strategic planning.

\section{Valuing a Strategic Real Option}

Strategy researchers have suggested that a number of corporate decisions can best be viewed through a strategic options lens (Bowman and Hurry 1993). These decisions include the termination of joint ventures (Kogut 1991), the management of multinational manufacturing networks (Kogut and Kulatilaka 1994), venture capital investments (Hurry et al. 1992), R\&D programs (Brealy and Myers 1981, Chapter 29, and see Mitchell and Hamilton 1987 for a managerial discussion), and some capital budgeting decisions (Dixit and Pindyck 1994). A common theme in all of these decisions is that they entail the use of a twostage process: In the first stage, a small investment is made that gives the company the right to participate in the project (i.e., the company purchases the option). Some time later, when more information is known, the second stage occurs when the company faces a choice about making a larger investment in the project (i.e., the company exercises the option).

For capital budgeting purposes, a real option must be analyzed multiple times. First, the company must decide if the real option should be purchased. The investment in the real option makes economic sense when the value of the option, as determined by an options valuation algorithm, exceeds the cost of the option. Later, if the company has purchased the real option, it must decide if and when to exercise the real option. This second evaluation is based on the difference between the then-prevailing value of the project and the exercise price of the option (this typically does not involve the use of options analysis, except in the case of a multistaged option investment ${ }^{1}$ ).

Real options analysis appears to present formidable problems for implementation. To demonstrate the feasible use of the real options approach, and its associated problems, we utilize an example of an option analysis performed recently by Merck. The data in our example are based on information provided to us by Merck during several conversations we held with the finance personnel at the company who performed this analysis.

\section{The Project}

In the early 1990s, Merck used option analysis to evaluate a proposed business relationship with a small biotechnology company (Sender 1994, Thackray 1995). This proposed relationship was called Project Gamma. Merck wanted to enter a new line of business that required the acquisition of a new technology from a small biotech firm code-named Gamma. Gamma had patented its technology but had yet to develop any commercial applications from it. Merck had proposed licensing this technology with the hope that a new product could be developed therefrom. Merck estimated that, after licensing the technology, it would take another two years of research and development activities before any product would be ready. Because of the preliminary nature of the technology, it was not certain that Merck could, in fact, develop a product, or, if a product were developed, what its commercial possibilities would be. If, after two years, it appeared that the new product was commercially feasible, then Merck would need to construct a plant to produce the product and make the associated marketing, working capital, and other start-up expenditures. These start-up requirements could take another year to complete.

Merck negotiated with Gamma to license the technology. Under the terms of the proposed agreement, Merck would pay Gamma a $\$ 2$ million license fee over a three year period. In addition, Merck would pay royalties to Gamma if and when the product came to market. Merck had the option to terminate the agreement at any time if it was dissatisfied with the progress of the research.

The proposed Gamma agreement resembles a call option and can be analyzed using option analysis. It should be noted that this use of an option valuation technique creates the theoretical value of the option; this theoretical value should be compared to the actual cost of the option, which equals the sum of the license fee plus the R\&D cost. For a small upfront fee, Merck purchased the right to benefit from any increase in the value of Gamma's technology. However, if this technology failed to produce a commercially viable product, then Merck was under no obligation to build the plant and incur the start-up costs. Additionally, Merck expected the start-up costs to be independent of the future value of the technology.

\section{Merck's Analysis}

To calculate the value of the option, Merck used the Black-Scholes model (Black and Scholes 1973), which requires values for five parameters. 
The first is the stock price. For this project, Merck took the expected present value of the cash flows from the project (i.e., the DCF value), assuming that the technology is successful and the plant is built. It is this value that has the variation, or the probability distribution, associated with it over the multiyear period. (Please note that stock price does not refer to Merck's stock price; instead, it refers to the value of the project.) The calculation of the stock price excludes both (a) the cash flows for building the plant and the associated start-up costs (these costs are considered in the exercise price portion of the calculation) and (b) the upfront licensing and development costs (these costs are considered in the cost of the option). The stock price calculation is based on Merck's best estimate as to the cash flows which would be generated by the project. This discounted cash flow valuation was made using traditional-net present-value techniques. In addition to the base case scenario, a number of sensitivity cases were run based on different assumptions about the success of the project. The base-case stock price was $\$ 28.5$ million; the four sensitivity case stock prices were $\$ 22.5, \$ 18, \$ 15.8$, and $\$ 15$ million, because of the use of a variety of less-favorable assumptions.

The exercise price is the cost of building the plant and the associated start-up costs that would be incurred if the decision is made to commercialize the technology. Merck estimated that these costs would total \$25.4 million.

The time to expiration is based on the expected time to develop the product and build the factory. This was varied over two, three, and four years; after four years, it was felt that competing products would enter the market, making entry by Merck unfeasible.

The volatility is based on the annual standard deviation of returns for biotechnology stocks. These stocks appear to have a similar level of risk as Project Gamma. A volatility of 0.5 was used in the analysis and was provided by Merck's investment banker.

The risk-free interest rate is based on the thenprevailing yield on two- to four-year Treasury bonds. An interest rate of $4.5 \%$ was used in the calculation of the option value.

Using these inputs, Merck calculated the BlackScholes option value for the base case scenario and each of the sensitivity cases. Merck also examined the value of the option assuming that it was either a two-year, threeyear, or four-year option. These 15 option values ( 5 cases $\times 3$ expiration dates) were compared to the cost of buying the option, which is equal to the costs of licensing and developing the technology (these upfront costs total an estimated \$2.8 million). Table 1 shows this analysis. This analysis shows that the value of the option exceeds the cost of the option (except in two cases), so Merck
Table 1 Project Gamma Option Valuation Analysis

\begin{tabular}{lllll} 
& \multicolumn{4}{c}{ Sensitivity Cases } \\
\cline { 2 - 4 } Base & $\#$ Case & $\# 1$ & $\# 2$ & $\# 3$
\end{tabular}

\begin{tabular}{|c|c|c|c|c|c|}
\hline \multicolumn{6}{|c|}{ Common parameters: } \\
\hline Stock price & $\$ 28.5$ & $\$ 22.5$ & $\$ 18.0$ & $\$ 15.8$ & $\$ 15.0$ \\
\hline Exercise price & 25.4 & 25.4 & 25.4 & 25.4 & 25.4 \\
\hline Interest rate & $4.5 \%$ & $4.5 \%$ & $4.5 \%$ & $4.5 \%$ & $4.5 \%$ \\
\hline Volatility & $50.0 \%$ & $50.0 \%$ & $50.0 \%$ & $50.0 \%$ & $50.0 \%$ \\
\hline \multicolumn{6}{|c|}{2 Year time horizon cases: } \\
\hline Option Value & $\$ 10.1$ & $\$ 5.9$ & $\$ 3.4$ & $\$ 2.4$ & $\$ 2.1$ \\
\hline Decision & Invest & Invest & Invest & Not invest & Not invest \\
\hline \multicolumn{6}{|c|}{3 Year time horizon cases: } \\
\hline Option Value & $\$ 11.9$ & $\$ 7.6$ & $\$ 4.8$ & $\$ 3.6$ & $\$ 3.2$ \\
\hline Decision & Invest & Invest & Invest & Invest & Invest \\
\hline \multicolumn{6}{|c|}{4 Year time horizon cases: } \\
\hline Option Value & $\$ 13.5$ & $\$ 9.0$ & $\$ 6.0$ & $\$ 4.6$ & $\$ 4.2$ \\
\hline Decision & Invest & Invest & Invest & Invest & Invest \\
\hline
\end{tabular}

Note. Investment decision is based on the value of the option relative to the $\$ 2.8$ cost of purchasing the option.

agreed to license the technology and begin working on its commercial development. For example, using the base case scenario and a three-year expiration date, Merck concluded that the Black-Scholes option value was \$11.9 million, and the three-year sensitivity case Number 2 has a value of $\$ 4.8$ million, both of which are far in excess of the $\$ 2.8$ million cost of the option, leading to a decision to invest.

\section{Limitations of the Quantitative Approach to Real Options}

The user of a quantitative model to value strategic real options faces a number of implementation problems (Lander and Pinches 1998). These problems generally fall into three categories: finding a model whose assumptions match those of the project being analyzed, determining the inputs to this model, and being able to mathematically solve the option pricing algorithm. We examine the first two problems below. (See Lander and Pinches 1998 for a discussion of tractability.)

\section{Modeling Assumptions}

The usefulness of a real options approach to quantitative decision making depends on the extent to which the characteristics of the investment proposal being evaluated match the assumptions of the option valuation model being used. The analogy between financial and real options 
is imperfect, making the use of financial option valuation models problematic for real options. Strategic options often lack some (and, perhaps many) of the explicit features of exchange-traded options. These differences determine whether formal option valuation models (such as the Black-Scholes model) are useful for managerial decision making.

In valuing strategic options, perhaps the most important assumption concerns the distribution of the underlying stock price. In the Black-Scholes formula, the stock price is assumed to follow a lognormal distribution, with a constant level of volatility. Over time, the distribution of stock prices gets wider, as the path of potential stock prices increases exponentially at the high end and asymptotically approaches zero at the low end. (Other option pricing models are based on different stock price distribution assumptions; for example, a mean-reverting process is often used for natural resource-based options.) The lognormal assumption may be inappropriate for a strategic option. Bollen (1999) notes that standard techniques for valuing real options typically ignore the product life cycle. For some products, such as semiconductors, the product life cycle has historically been quite short: Sales rise rapidly, and then fall rapidly as a new, better product takes over the market. Given this sales pattern, the standard lognormal distribution is inappropriate for a real options model. ${ }^{2}$

In the Merck example, the use of the Black-Scholes model is problematic because of its embedded assumptions about the distribution of future stock prices. The Black-Scholes model shows that the longer Merck could wait to exercise its option, the more valuable the option becomes (see Table 1). This increase in value is due to (1) the use of the lognormal stock price distribution assumption, under which the underlying stock price has more time to move to higher values, and (2) the present value of the exercise price is lower for a longer option. Under a strategic analysis, however, the longer Merck waits to exercise its option, the lower the value of the project. This is because the bulk of the value of the project comes from patent protection. Without the patent, Merck assumed that its competitors would be able to copy the product and drive economic rents down to zero. Because the patent has a fixed expiration date, the longer Merck waits to exercise the option (by building the plant), the less time is left on the patent and the lower the overall economic value.

Merck could have adjusted its use of the Black-Scholes model to account for the negative effects of having to wait longer to exercise the option. To do this, Merck would have had to create a separate set of inputs for their two-year, three-year, and four-year analyses. Instead of using the same initial stock price and exercise price for the two-year, three-year, and four-year options, Merck should have performed three separate calculations of the expected stock price assuming that the initial R\&D took two years, three years, or four years (the longer time horizons would have had lower initial stock prices). Similarly, the exercise prices could be adjusted for the additional inflation factors. These values could then be used with a separate Black-Scholes model for each time frame.

\section{Determining the Inputs}

The effective use of a quantitative model to value a potential strategic investment is limited by the need to calculate the model's inputs. If the inputs are improperly calculated, then the results from using the model will be incorrect. $^{3}$

In examining the Merck case, we note that the company faced a number of problems in determining the values of the model's inputs.

Stock Price. For an exchange-traded option, the current and future stock prices are readily observable to the option holder. These stock prices are meaningful to the option holder in the sense that the option holder can readily buy or sell shares at this price to realize the profit from (or to cut the loss on) an option position. In contrast, for real options, the analogous stock price may be unknown and/or unactionable. For example, in the case of an option on a plot of vacant land, the developer does not have an active market to turn to for the current value of the land. Similarly, strategic options in the form of research projects do not have a readily observable stock price, as the outcome of the research is unknown until the project is completed. The lack of a visible stock price may also make it difficult to draw conclusions about the appropriate course of action at the time of the option's expiration.

To calculate the stock price, Merck used its best estimate of the project's net present value. Therefore, any errors made in the NPV calculation became errors in the option valuation calculation. A common approach to uncertainty when using discounted cash flow techniques is to create a set of sensitivity cases based on different possible outcomes. As noted above, Merck created a base case and then a series of sensitivity cases based on a "what if something went wrong" reasoning. Interestingly, Merck did not produce a series of sensitivity cases assuming that things went better than expected. Also, Merck did not attempt to assess the likelihood of the different downside scenarios that it created.

Volatility. Merck used the volatility of stocks with a similar risk profile as its input. For many strategic investments, however, there are no publicly traded instruments whose risk profile matches that of the proposed 
investment. In general, it is becoming easier to find risk profile information. Amram and Kulatilaka (1999) note that the number of instruments traded on financial markets has continually grown, increasing the chances that a suitable source of volatility (and sometimes stock price) information can be found.

Time to Expiration. For strategic real options, there is often no set time to expiration. For example, a research project could be extended for a longer period of time, and an investment in a new product distribution system indefinitely retains the option to add additional products. As noted above, the interaction of the time to expiration and the stock price distribution assumptions can produce severe problems in the valuation of real options.

Exercise Price. Option valuation models assume that the exercise price of the option is fixed in advance. If this is not the case, then the value of the option changes dramatically. Many investments have some of the characteristics of real options but do not have a fixed exercise price. For example, Kogut (1991) suggested that participating in a joint venture gives a firm an option to buy out its partner-a form of a call option. If the venture is successful, then one partner is likely to exercise this option and purchase the other partner's ownership interest. In most joint ventures, the price paid to buy out the partner's interest is based on the prevailing fair market value at the time of the buyout. In terms of valuation, this is not an option because the seller (and not the call option holder) gets the benefit of any price appreciation. Accordingly, it is inappropriate to use a standard stock option valuation model to evaluate the real option aspect of a joint venture agreement.

In the Merck example, the company used the estimated expenditures for building the plant and incurring the associated start-up costs as the exercise price. At the time of exercise, however, Merck will face a number of choices about how to commercialize the technology (if the R\&D is successful). For example, Merck could license the technology to another firm, or choose to build a plant of small or large size, etc. These choices affect the calculation of the exercise price.

\section{The Role of Option Analysis in Strategic Planning}

The real options approach to strategic analysis presents planners with a dilemma. Options are a theoretically attractive way to think about the flexibility inherent in many investment proposals; however, the use of the methodology presents many practical difficulties, which can lead all but the most careful users to make erroneous conclusions. The complexity of the options approach can also make it difficult to find errors in the analysis, or overly ambitious assumptions used by optimistic project champions. These practical difficulties may explain the limited use of real options analysis in strategic planning.

One approach to solving the problem of misspecified option valuation models is to create a more advanced, customized option valuation algorithm that better matches the characteristics of the investment proposal. The design, development, and computational solution of these advanced option models is often beyond the capabilities of corporate managers. Given the inherent difficulties in creating and solving these models, it is not surprising that advanced real options models are seldom used in strategic decision making.

The Merck example shows that the benefit of the real options approach was not simply the improved estimation. In fact, there are several technical objections to their estimation, ranging from their application of the BlackScholes model without correcting for the shortfall in the equilibrium cash flows (see Kogut and Kulatilaka 1994 for an applied analysis of this model) to the reasonableness of a random walk process to the cash flows. It is important to remember that numerical results are unlikely to be very sensitive to reasonable mathematical specifications of the cash flows' dynamics. In unpublished estimations, we found that linear specifications of the option generate values similar to those found by Merck's analysis using the Black-Scholes formula (available upon request). Whereas small deviations are worth fortunes in financial markets, they are fairly inconsequential in product markets.

This point echoes Bowman's (1963) finding that the value of many decision rules lies more in the requirement for consistency than in the perennial search for optimality. In fact, the value of real options analysis is often found in the implications for project design rather than in the actual planning evaluation. For Merck, the key insight was to see the license as granting the right to exercise a future investment. Ordinarily, one might want to assign probabilities to good and bad investment scenarios and then take their mean values to estimate cash flows to understand whether to buy the license. The option perspective says that because the investment decision is contingent on buying the option, it is not reasonable to evaluate the license decision as if one must then make the future investment. Similarly, options analysis suggests the value of experimentation by breaking up the investment into a series of smaller sequential projects.

A formal quantitative valuation model is just one part of the overall strategic planning and capital allocation 
process. When making these decisions, companies need to perform both financial and strategic analysis (Myers 1984). Multiple forms of analysis are advantageous because the different methods act as a check on each other. For example, forecasting cash flows is notoriously difficult, making it problematic to use a capital allocation system that relies solely on financial analysis. Similarly, strategic analysis does not indicate whether the project offers a return that justifies its inherent risk. Within the quantitative analysis step, strategic planners choose an appropriate valuation tool (e.g., options or DCF) that matches the investment proposal.

Finally, we note that one potential advantage of using the real options analytic approach is that it might change the type of investment proposals that are reviewed. As Kogut and Kulatilaka (2001) note, an option perspective inverts the usual thinking about uncertainty absorption found in the organizational literature. If options are seen as a legitimate approach to analyzing proposals, then more option-like proposals may be considered. This increase can come from both a change in the types of new proposals that are generated (i.e., managers look for options to invest in), and from rethinking nonoption proposals to convert them into options. For example, one company we spoke with indicated that its planners were asked to consider a major capital expenditure to purchase new tooling for some of the firm's factories. The planners converted this proposal into an option by suggesting that a pilot program be undertaken; if successful, then all of the factories would receive the new tooling. Thus, an options approach encourages experimentation and the proactive exploration of uncertainty. As more recent traditional organizational theories argue, this engagement in exploration is indeed a revolution in thinking.

\section{Acknowledgments}

The author wishes to thank William Hamilton, Paul Kleindorfer, Arie Lewin, and Daniel Levinthal for their helpful comments on an earlier draft of this paper, and Bruce Kogut for his help on its various drafts. Thanks are due to the Reginald $\mathrm{H}$. Jones Center for financial support.

\section{Endnotes}

${ }^{1}$ An example of a multistaged real option is the new drug development process. The drug company must decide whether to continue or abandon a project after each of the many steps in the process, from initial $R \& D$ to preclinical testing to the later phases of testing (Copeland et al. 1995, Chapter 15).

${ }^{2}$ Bollen (1999) derives an option valuation model that incorporates assumptions about a product life cycle.

${ }^{3}$ Colloquially, this is known as "garbage in, garbage out."

Accepted by Arie Lewin.

\section{References}

Amram, Martha, Nalin Kulatilaka. 1999. Real Options: Managing Strategic Investment in an Uncertain World. Harvard Business School Press, Boston, MA.

Astely, W. Graham. 1985. Administrative science as socially constructed truth. Admin. Sci. Quart. 30(4) 497-513.

Black, Fischer, Myron Scholes. 1973. The pricing of options and corporate liabilities. J. Political Econom. 81(May-June) 637-659.

Bollen, Nicolas P.B. 1999. Real options and product life cycles. Management Sci. 45(5) 670-684.

Bowman, Edward H. 1963. Consistency and optimality in managerial decision making. Management Sci. 9(2) 310-321.

- Dileep Hurry. 1993. Strategy through the option lens: An integrated view of resource investments and the incremental choice process. Acad. Management Rev. 18(4) 760-782.

Brealey, Richard, Stewart Myers. 1981. Principles of Corporate Finance. McGraw-Hill Book Company, New York.

Cohen, Michael D., James G. March, Johan P. Olsen. 1972. A garbage can model of organizational choice. Admin. Sci. Quart. 17 1-25.

Copeland, Thomas E., Philip T. Keenan. 1998. How much is flexibility worth? Mckinsey Quart. 2 38-49.

—, Tim Koller, Jack Murrin. 1995. Valuation: Measuring and Managing the Value of Companies, 2nd ed. John Wiley \& Sons, Inc., New York.

Coy, Peter. 1999. Exploiting uncertainty: The "real options" revolution in decision making. Bus. Week. June 7. pp. 118-124.

Dixit, Avinash K., Robert S. Pindyck. 1994. Investment Under Uncertainty. Princeton University Press, Princeton, NJ.

Hurry, Dileep, Adam T. Miller, Edward H. Bowman. 1992. Calls on high-technology: Japanese exploration of venture capital investments in the United States. Strategic Management J. 13(2) 85101.

Kogut, Bruce. 1991. Joint ventures and the option to expand and acquire. Management Sci. 37(1) 19-33.

_, Nalin Kulatilaka. 1994. Operating flexibility, global manufacturing, and the option value of a multinational network. Management Sci. 40(1) 123-139.

- _ 2001. Capabilities as real options. Organ. Sci. 12(5).

Lander, Diane M., George E. Pinches. 1998. Challenges to the practical implementation of modeling and valuing real options. Quart. Rev. Econom. Finance 38 537-567.

Mitchell, C. R., William F. Hamilton. 1987. Managing R\&D as a strategic option. Res. Management 31 15-22.

Myers, Stewart C. 1984. Finance theory and financial strategy. Interfaces 14(1) 126-137.

Nichols, Nancy A. 1994. Scientific management at Merck: An interview with CFO Judy Lewent. Harvard Bus. Rev. 72(1) 88-99.

Sender, Gary L. 1994. Option analysis at Merck. Harvard Bus. Rev. 72(1) 92.

Thackray, John. 1995. A Merck case study. Planning Rev. 23(3) 47.

Trigeorgis, Lenos. 1996. Real Options: Managerial Flexibility and Strategy in Resource Allocation. The MIT Press, Cambridge, MA. 